\title{
UMA PESQUISA SOCIOCLÍNICA NA FRANÇA: \\ NOTAS SOBRE A ANÁlise INSTITUCIONAL ^ \\ http://dx.doi.org/10.1590/1984-0292/1309
}

\author{
Cinira Magali Fortuna, ${ }^{I} \star \star$, Gilles Monceau ${ }^{I I}$, \\ Silvia Valentim ${ }^{I I}$, Khadija Lalah El Mennani ${ }^{I I}$ \\ ${ }^{I}$ Universidade de São Paulo, São Paulo, SP, Brasil \\ ${ }^{I I}$ Université de Cergy-Pontoise, Cergy-Pontoise, France
}

\section{Resumo}

Esse texto tem por objetivo apresentar e discutir o processo de produção de uma pesquisa socioclínica sobre a parentalidade, desenvolvida na França, em Gennevilliers, durante 2011 e 2012. Baseou-se no referencial teórico da análise institucional, linha socioclinica. Os dispositivos para a produção dos dados da pesquisa foram observação participante, grupos de discussão com profissionais e pais, entrevista em domicílio, entrevistas informais e sessões de restituição. O processo de montagem e desenvolvimento desse tipo de pesquisa indica uma permanente tensão a ser explorada entre a intencionalidade dos demandantes $e$ dos pesquisadores, o que faz a análise de implicação indispensável.

Palavras-chave: análise institucional; pesquisa interdisciplinar; pesquisa participativa baseada na comunidade.

\section{Socio-clinical research in France: NOTES ON INSTITUTIONAL ANALYSIS}

\begin{abstract}
This study aims to present and discuss the process of producing a socioclinical research on parenting, developed in Gennevilliers, France during 2011 and 2012. The theoretical framework was based on institutional analysis, socio-clinical perspective. The devices for the production of research data include participant observation, discussion groups with professionals and parents, household interview, informal interviews and restitution sessions. The development of this kind of research indicates a constant tension to be explored between the intentionality of claimants and researchers which makes the analysis of implication indispensable.

\footnotetext{
* Artigo original, inédito, sem utilização de dados primários. É fruto de pesquisa de pós-doutorado, financiada através de bolsa de estudos pela Fundação de Amparo à Pesquisa do Estado de São Paulo, processo número: 2011/14440-7. Todos os autores participaram igualmente em todas as fases de elaboração do artigo. Preto. Av Bandeirantes, 3900, prédio da EERP, sala 153. Campus da USP - Monte Alegre. 14040900 - Ribeirão Preto, SP - Brasil.E-mail: fortuna@eerp.usp.br, gilles.monceau@orange.fr, silvia.valentin@gmail.com,kadla78@hotmail.com
}

$\star \star$ Endereço para correspondência: Universidade de São Paulo, Escola de Enfermagem de Ribeirão
\end{abstract}


Keyword: institutional analysis; interdisciplinary research; community-based participatory research.

\section{INTRODUÇão}

A análise institucional, que foi desenvolvida na França nas décadas de 1960 e 1970, por autores como Georges Lapassade (1983) e René Lourau (1995), atualmente segue em desenvolvimento por intermédio da obra de autores como Lamihi e Monceau (2002); Monceau (2011; 2012); Guillier e Samson (1997), entre outros.

No Brasil, concepções do movimento institucionalista vem sendo aplicadas em pesquisas na saúde coletiva (L'ABBATE, 2003; MERHY, 2002; FRANCO, 2007; SPAGNOL; L'ABBATE, 2010, FORTUNA et al., 2012), na psicologia (PAULON; ROMAGNOLI, 2010; ROCHA, 2006; NASCIMENTO e SCHEINVAR, 2010) e na educação (MOURÃO et al., 2007; PEREIRA, ANDRADE, 2005).

Segundo Bonny e Demailly (2012), a instituição é um conceito polissêmico e existem ao menos quatro formas de compreender o termo, a saber: a) num senso culturalista para designar o conjunto de valores, normas e modelos de conduta dotadas de uma certa regularidade; b) do ponto de vista do positivismo jurídico, centrado no conjunto de processos de formalização pelo direito; c) em uma perspectiva antropológica, interessando-se pelas modalidades de apreender os jogos sociais tomados como universais pelos coletivos humanos e d) segundo uma aproximação que coloca no centro a análise e o processo de ligações sociais ao poder político.

No presente texto são consideradas as definições de René Lourau (1995; 2007) e de Monceau (2012), que afirmam: as instituições são lógicas abstratas, mas também materiais, resultantes de um processo dialético constituído por uma parte mais fixa (o instituído) que é a parte mais aparente delas, uma parte mutável (o instituinte), que provoca rupturas com os pactos tradicionais e um terceiro momento chamado de institucionalização em que o instituinte é incorporado pela instituição passando a ser instituído.

As instituições frequentemente são capazes de produzir justamente o oposto do propósito para o qual foram fundadas, por exemplo: a instituição psiquiatria que se materializava nos manicômios, produzia a exclusão e a loucura, quando anunciava como tarefa o cuidado aos doentes mentais.

Outra característica das instituições é que elas fabricam e são fabricadas ao mesmo tempo por seus agentes, ou seja, gestores, trabalhadores e usuários de uma dada instituição, fabricam e colocam em ação as normas e regras e ao mesmo tempo são também produzidos nessa dinâmica. Dito de outra forma : há uma produção de subjetividades nas instituições.

Ao analisar as instituições em suas contradições, René Lourau (1995) e seus orientandos vão propor a análise delas através de um processo coletivo denominado de análise institucional. Por coletivo toma-se a conjugação de dois 
planos inseparáveis, o plano das formas e os planos das forças. O plano das formas relaciona-se ao plano da organização, do instituído e o plano das forças é o plano do instituinte, das relações (ESCÓSSIA, 2009).

Há uma importante influência da psicanálise no constructo teórico da análise institucional por considerar-se que as instituições possuem uma parte não visível. Inspirou-se no princípio de que há uma resistência à análise - como no processo psicanalítico - em que mesmo havendo interesse, inclusive com o pagamento, o analisando tenta impedir o processo analítico (MONCEAU, 2012).

A análise institucional vai questionar o lugar dos pesquisadores como especialistas capazes de decifrar uma realidade e manter uma neutralidade quanto ao campo e objeto de estudos. René Lourau $(1995 ; 2007)$ em sua obra faz certa denúncia de que as pesquisas e seus resultados são influenciados por quem as encomenda e financia. Ele construiu o conceito de análise de implicação, um processo de reflexão sobre nossas múltiplas ligações com as instituições (ALTOÉ, 2004; MONCEAU, 2008).

Assim, a pesquisa na análise institucional opera com a análise coletiva dos envolvidos nos locais que materializam as instituições, ou seja, nos estabelecimentos e nas organizações. Ela imprescinde da análise de implicação, assim como a análise da demanda, ou seja, do motivo que desencadeou a análise institucional. Também prevê a análise da oferta, daquilo que os analistas e/ou pesquisadores ofertam.

A pesquisa que se desenvolve no processo de análise institucional tem como objeto de investigação, ao mesmo tempo, o processo de negociação, a análise em si, a montagem de estratégias e os efeitos produzidos na análise. Desse modo, os processos analíticos não são espontâneos e devem ser engendrados através de dispositivos que constituem essas estratégias.

Podemos dizer que a pesquisa socioclínica para a análise institucional, é um processo de produção de dispositivos postos em ação e que são foco da análise, pois engendram efeitos.

Os sujeitos envolvidos na pesquisa socioclínica reelaboram o sentido que atribuem as suas ações e dessa forma os pesquisadores têm acesso a um processo reflexivo que está em produção. A pesquisa transforma os fatos que estuda, ao mesmo tempo em que contribui para a produção dos mesmos (MONCEAU, 2005).

O processo de pesquisar é uma intervenção uma vez que aciona análises coletivas que modificam as práticas e as relações (MONCEAU, 2005; ROCHA, 2006; PEZZATO; L'ABBATE, 2011). Esse processo investigativo é dinâmico e complexo, possui diversas formas de ser desencadeado e não segue protocolos preestabelecidos. A pesquisa se cria e se recria no seu desenvolvimento, assim, a partilha e a análise de uma investigação realizada nessa modalidade de investigação podem contribuir para a "invenção" de outros modos de investigar. 
O objetivo desse artigo é apresentar e discutir o processo de produção de uma pesquisa socioclínica sobre a parentalidade, desenvolvida na França, em Gennevilliers, durante 2011 e 2012. Se justifica pelo crescente número de investigações que vêm adotando modalidades de investigar pautados na colaboração e produção conjunta entre pesquisadores e profissionais dos serviços prestados (PAULON; ROMAGNOLI, 2010; PEZZATO; L'ABBATE, 2011; FORTUNA et al., 2011; CAMPOS, 2011).

\section{O CONTEXTO DA INVESTIGAÇÃO}

A cidade de Gennevilliers faz parte da região da grande Paris e conheceu uma expansão nos anos de 1960 e 1970, vindo a se transformar pela industrialização e pela atração de famílias em razão da oferta de empregos (MENNANI, 2012). Ficou conhecida por sua tradição de esquerda militante por abrigar numerosos trabalhadores organizados em sindicatos. Também foi alvo de uma política de urbanização do pós-guerra com a construção de imensos edifícios denominados HLM, Habitation a Loyer Moderé - habitações com aluguel moderado sem o acompanhamento da infraestrutura urbana necessária (MENNANI, 2012).

Após os anos 2000, com a crise econômica e movimentos imigratórios de outros países, diversos imigrantes ali se instalaram. Assim, a cidade vem lidando com desemprego e outros problemas urbanos: abandono escolar, violência, uso de drogas, entre outros (MENNANI, 2012). Hoje é considerada um polo de desenvolvimento contando com um importante porto fluvial e muitas atividades relacionadas à indústria (FRANÇA, 2013).

Em 2012 contava com 41.400 habitantes, sendo que desses 15.368 eram jovens, com menos de 25 anos. Dados de 1999 apontavam que 52,6\% da população de menores de 18 anos, eram de origem estrangeira, com pelo menos um dos pais imigrante, vindos especialmente da África do Norte e da Turquia.

A influência de diversas culturas e religiões (com destaque a cultura árabe e a religião muçulmana) se fazem presentes e constituem um desafio para os profissionais da cidade, pois colocam em evidência a pluralidade e a diferença de modos de viver e de se relacionar.

Nos últimos anos, Gennevilliers vem se destacando com suas políticas sociais sobre os bairros chamados prioritários, com ações tais como: atividade educativa local, atividades para o tempo livre, programa para o sucesso escolar, ações locais de prevenção e segurança, plano local para a inserção no trabalho, entre outras.

Assim, a escola e as ações educativas ocupam um lugar de destaque. Podemos dizer que na França, e, por conseguinte, em Gennevilliers, a escola é uma instituição central, estando relacionada com a fundação da própria república francesa.

As transformações sociais relacionadas ao capitalismo mundial integrado (GUATTARI; ROLNIK, 1985) também transformaram a escola, que não mais necessariamente assegura a produção de cidadãos para a manutenção do Estado e do status quo. 
Não por acaso, em 2012, foi lançado na França, pelo Ministério da Educação, um movimento para refundação da escola. Essa é um dos espaços mais evidentes da materialização do poder do Estado nos territórios sociais franceses e se dirige a dois públicos: pais e estudantes.

A prefeitura e o poder público, que financiam inúmeras associações, tomam como população-alvo esses dois públicos, propondo ações culturais, educativas, sociais que gravitam em torno da escola, mas tendo-a como centro.

Nas análises dos profissionais da prefeitura e das associações, uma questão começou a incomodar: porque os pais não participam? Onde estão os pais que jamais vemos? Como alcançá-los, já que constituem nossa população-alvo? Essas questões compuseram uma demanda de pesquisa para a Universidade de Cergy-Pontoise, que possui um de seus campi em Gennevilliers.

A pesquisa foi desenvolvida por um grupo de pesquisadores interessados na temática da parentalidade e no referencial teórico metodológico da análise institucional, incluindo mestrandos, doutorandos e professores sob coordenação de um pesquisador que estuda a temática há muitos anos e que é um dos autores desse artigo.

\section{A ANÁlise de IMPLICAÇão}

Segundo Lourau (1995), a análise de implicação é um processo reflexivo indispensável na análise institucional e há dois tipos de implicação: a primária e a secundária. A implicação primária é composta pelo conjunto de ligações mais imediatas que se estabelecem entre o staff interveniente e a equipe do estabelecimento onde ocorre a análise institucional. A implicação secundária é aquela resultante de nossas ligações com as inúmeras instituições, que nos atravessam e nos conformam.

Nossa análise de implicação secundária indica ao menos ligações com três instituições. A primeira é a parentalidade que nos convoca a pensar sobre nossas ligações e rupturas aos lugares de pais, mães e filhos, lugares de poder e saber que envolvem a educação e a transmissão de valores familiares.

A segunda instituição é a escola com os professores que "sabem" o conhecimento oficial e os estudantes que "não sabem", mas precisam saber. Todos os pesquisadores são ligados à instituição escola por suas profissões, pela sua formação e/ou pelo tema de suas pesquisas.

A terceira instituição é a pesquisa, uma possibilidade de afirmação de poderes e saberes e também exigência do trabalho universitário.

Essas três instituições mais evidentes e a forma como nos ligamos a elas evidenciam interesses, desejos, experiências e afetos que conformaram nosso olhar, nossa postura, nossa prática investigativa e nossas relações com os coletivos onde a pesquisa se desenvolveu. 


\section{Produzindo dispositivos}

Consideramos que o processo da pesquisa-intervenção iniciou-se com a formulação da demanda da mesma, engendrada também pela oferta dos pesquisadores. Para a análise institucional, quando há uma demanda, há também uma oferta. Nesse sentido, há de se analisar o que temos ofertado enquanto investigadores.

Para continuá-la e acionar análises coletivas seria necessário montar dispositivos, arranjos capazes de fazer ver e falar as instituições em análise.

Estamos considerando como dispositivos os arranjos passageiros, as montagens provisórias, que permitem a desestabilização dos modos instituídos de funcionamento, favorecendo assim a análise coletiva das forças instituintes, e em processo de institucionalização.

Pode ser uma técnica, um evento, mas precisa ter a capacidade de provocar a "fala" das instituições. Segundo Lourau (2004), há momentos em que as instituições falam pelo ventre de agentes que nela trabalham, como um ventrículo.

Assim, as pesquisas nessa vertente da análise institucional vão se valer de técnicas de investigação já conhecidas, como por exemplo a observação participante, as entrevistas, entre outras, mas diferentemente de investigações mais clássicas, essas técnicas não são definidas $a$ priori e nem possuem compromissos fixos com normativas estruturadas (sequências, ordenações rígidas, entre outros).

Os dispositivos são postos em ação e analisados considerando seus efeitos, o processo, as conexões acionadas e desfeitas.

No caso da pesquisa sobre a parentalidade, coletivos organizados foram identificados entre os quais o PRE (Programme de Reussit Educative - Programa para o sucesso escolar), a casa da infância do bairro Luth e as reuniões dos profissionais relacionados com a infância e a juventude.

Nesses espaços foram acionados dispositivos para colocar em análise as ações desenvolvidas que tinham por população-alvo os pais e os estudantes. Assim, um dos dispositivos foi a roda de conversa com trabalhadores.

Outro dispositivo foi incluir nesses espaços os pais organizados, ou seja, os representantes dos pais, para falarem de suas expectativas e percepções. A presença dos pais nas discussões, ainda que pais militantes, produziu uma tensão por manifestar concretamente a ausência desses, os anseios e os desencontros de posições.

Certo alinhamento entre as diversas discussões nos diferentes grupos era assinalado pelos pesquisadores, o que permitia um amadurecimento da análise já efetuada, assim como a complexificação da mesma. Por exemplo, se num primeiro momento a ausência dos pais significava indiferença, no processo analítico a mesma foi revestindo-se de outras possíveis características como o afastamento, pelo receio do controle que os profissionais fazem ao prestar serviços. Em uma das sessões de análise foi identificado que é preciso contar detalhes da vida privada para conseguir acesso à inclusão numa atividade de acompanhamento escolar. 
Outra estratégia utilizada foi a apresentação de experiências de outras localidades. No caso, foram apresentados aspectos da realidade brasileira e canadense, com relação à temática em discussão naquele momento, que era o lugar do pai. Foi apresentado ao grupo presente que essa participação, em geral, é lida com desconfiança pelos profissionais quando, por exemplo, o mesmo acompanha os filhos aos serviços de saúde no Brasil e os profissionais lhe perguntam: "mas onde está a mãe?"

O efeito produzido pela inclusão de experiências diferentes e externas foi o de deslocar as análises realizadas de um nível mais local, mais doméstico, para algo mais geral presente não apenas na França, mas em outros países como no Brasil e no Canadá. Isso permitiu ao grupo refletir sobre as próprias particularidades com relação à presença e à ausência dos pais na escola e também permitiu identificar aspectos que não são específicos da instituição escola, pois manifestam-se na saúde e nem são próprios de Genneviliers, uma vez que ocorrem em outras localidades.

Além das discussões coletivas com profissionais e pais, outro desafio se impunha: abordar os pais que não frequentavam as instâncias formais. A entrevista informal foi o dispositivo adotado, sendo realizada nos espaços públicos como praças, calçadas, nos momentos de entrada e saída da escola, entre outros. Foram conversas mais informais, não gravadas e nem transcritas, registradas no diário de campo do pesquisador, que permitiram uma livre expressão sobre o tema. Essas entrevistas forneceram informações importantes que foram apresentadas aos coletivos de discussão.

A observação participante foi realizada por uma das pesquisadoras em seu estágio formal vinculado ao mestrado. Um diário de campo foi produzido e constitui-se material empírico.

Outro dispositivo dessa pesquisa-intervenção foi a entrevista em domicílio, no espaço da casa de pessoas que permitiram o acesso e que foram aleatoriamente selecionadas, a partir da observação participante em um dos equipamentos sociais do território.

Uma das pesquisadoras acompanhou uma moradora em suas atividades de levar crianças na escola, fazer compras em outra localidade e em atividades quotidianas no domicílio.

Esse processo permitiu identificar as inúmeras dificuldades - transporte coletivo, financeiras para locomoção, a relação com o tesouro público e com os benefícios sociais, entre outras. Também permitiu identificar a organização da vida familiar em função da organização da vida escolar. Os horários da escola determinavam os demais horários na casa, de modo que, a ausência de aulas desestruturava a programação familiar. Assim, a instituição escola se presentificava nas relações familiares, ordenando-as. 
Outras pessoas foram entrevistadas no domicílio, fornecendo pistas para a compreensão da ausência, ou melhor, desse outro modo de presença nos serviços prestados.

A enquete por telefone também foi utilizada para obtenção de informações de outras organizações que não participavam dos coletivos de discussão. Assim, diretores de creches e escolas foram entrevistados.

Durante o processo de pesquisa, reuniões de análise de dados foram realizadas pelos pesquisadores na perspectiva de junção dos dados produzidos e análise das estratégias adotadas. Esse processo auxiliou a organizar e materializar a produção em um formato que permitisse outras análises além daquelas realizadas coletivamente.

Por fim, destacamos o dispositivo denominado sessões de restituição nas quais as análises dos pesquisadores, produzidas por todos esses dispositivos, foram apresentadas e discutidas com os profissionais e demandantes da pesquisa. Nessa etapa, a demanda por simplificação da problemática e por apresentação de soluções facilmente implementáveis foram explicitadas aos pesquisadores.

O coletivo de profissionais, pais e interessados, ocorreu em três sessões abertas e analisou novamente os pontos chaves apresentados pelos pesquisadores, evocando outros exemplos que confirmaram as análises, mas também as refutaram, manifestando uma resistência às mesmas e também permitindo outras interpretações.

Assinalamos que o trabalho dos pesquisadores é complexo, em especial nesse momento da restituição, pois compreende receber a "depositação" das expectativas dos participantes e demandantes da investigação para que se apresentem as soluções aos problemas. Nesse caso, é preciso diferenciar o trabalho dos pesquisadores que é o de promover e facilitar análises coletivas, e o trabalho dos demandantes da pesquisa e do coletivo que é produzir suas respostas e outras interrogações. O esquivar-se do lugar de especialista e de quem tem e pode "dar respostas" é desejável e imperativo nesse tipo de investigação.

Dessa forma, o interjogo de desejos e interesses de todos os envolvidos na pesquisa pressupõe a construção de estratégias não definidas a priori como nas pesquisas mais tradicionais. Nesse sentido, destacamos que, na França, a possibilidade de se criar os dispositivos que serão utilizados no decorrer da pesquisa durante o desenvolvimento da mesma é viável, pois as exigências éticas não solicitam descrição de todos os passos metodológicos antes do início da investigação.

Ao mesmo tempo, preceitos éticos como garantia do anonimato, confidencialidade, conhecimento e discussão dos resultados, entre outros, estão assegurados pelo próprio processo, pois a pesquisa socioclínica se faz com os participantes e não sobre eles.

A pesquisa socioclínica demanda reflexões quanto aos efeitos produzidos, entendendo-os como efêmeros e provisórios, considerando que a mesma é incapaz de abarcar a complexidade das relações sociais. 
No caso dessa pesquisa, para fins de ilustração, citamos como "efeitos" desse tipo de metodologia: a revisão dos saberes e poderes dos investigadores oriundos da universidade, o que interroga essa instituição como locus de um saber soberano; a gestão de políticas sociais atravessadas pelas lógicas empresariais que simplificam, dividem e categorizam as pessoas na perspectiva de responder necessidades complexas com medidas tidas como eficientes e eficazes, entre outras.

A pesquisa tem por meta justamente a restituição da complexidade e da relatividade de olhares, pois trata-se de algo em movimento sobre o movimento.

\section{CONSIDERAÇões FINAIS}

O presente artigo apresentou e discutiu o processo de uma pesquisa socioclínica realizada na França, com a produção de dispositivos.

Certamente não servirá de guia para outras investigações tendo o intento justamente de colocar em evidência a impossibilidade da simples reprodução de técnicas de pesquisa a priori, quando se trata de investigações com o aporte teórico metodológico da análise institucional indicando a necessidade da criação de dispositivos adequados à temática e ao contexto.

Sua contribuição é a apresentação de conceitos da análise institucional e da pesquisa socioclinica de uma forma aplicada. 


\section{REFERÊNCIAS}

ALTOÉ, S. (Org.). René Lourau: analista institucional em tempo integral. São Paulo: Hucitec, 2004.

BONNY, Y.; DEMAILLY, L.(Org.). L'institution plurielle: le regard sociologique. Villeneuve d'Ascq: Septentrion, 2012.

CAMPOS, R. O. Fale com eles! o trabalho interpretativo e a produção de consenso na pesquisa qualitativa em saúde: inovações a partir de desenhos participativos. Physis, [online], v. 21, n. 4, p. 1269-1286, out./dez. 2011. Disponível em: <http:// dx.doi.org/10.1590/S0103-73312011000400006>. Acesso em: 14 maio 2014.

ESCÓSSIA, L. O coletivo como plano de criação na Saúde Pública. Interface, (Botucatu), Botucatu, v. 13, supl. 1, p. 689-694, 2009. Disponível em : <http:// www.scielo.br/scielo.php? pid=S1414-32832009000500019\&script=sci arttext>. Acesso em: 20 abr. 2014.

FORTUNA, C. M. et al. O enfermeiro e as práticas de cuidados coletivos na estratégia saúde da família. Rev. Latino-am. Enferm., v. 19, p. 581-588, 2011. Disponível em: <http://dx.doi.org/10.1590/S0104-11692011000300018>. Acesso em: 02 jun. 2014.

FORTUNA, C. M. et al. Notas cartográficas do trabalho na Estratégia Saúde da Família: relações entre trabalhadores e população. Rev. esc. enferm. USP, São Paulo, v. 46, n. 3, p. 657-664, jun. 2012.

FRANÇA. Site oficial da prefeitura de Genneviliers. 2013. Disponível em: $<$ http://www.ville-gennevilliers.fr/> Acesso em: 11 maio 2014.

FRANCO, T. B. Produção do cuidado e produção pedagógica: integração de cenários do sistema de saúde no Brasil. Interface (Botucatu), Botucatu, v. 11, n. 23, p. 427-438, set./dez. 2007.

GUATTARI, F.; ROLNIK, S. Micropolítica: cartografias do desejo. São Paulo: Ática, 1985.

GUILLIER, D.; SAMSON, D. Implication: des discours d'hier aux pratiques d'aujourd'hui. Les Cahiers de l'implication. Revue d'analyse institutionnelle, [S.1.], n. 1, p. 17-29, 1997.

L'ABBATE, S. A análise institucional e a saúde coletiva. Ciênc. saúde coletiva, Rio de Janeiro, v. 8, n. 1, p. 265-274, 2003. 
LAMIHI, A.; MONCEAU, G. Instituition et Implication: 1'oeuvre de René Lourau. Paris: Sylepse, 2002.

LAPASSADE, G. Grupos, organizações e instituições. 2. ed. Rio de Janeiro: Francisco Alves, 1983.

LOURAU, R. Análise institucional. Petrópolis, RJ: Vozes, 1995.

LOURAU, R. René Lourau na UERJ - 1993. Análise Institucional e Práticas de Pesquisa. Mnemosine, Rio de Janeiro, v. 3, n. 2, 2007. Disponível em: <http:// www.mnemosine.com.br/ojs/index.php/mnemosine/issue/view/24>. Acesso em: 12 abr. 2014.

LOURAU, R. O instituído contra o instituinte. In: ALTOÉ, S. (Org.). René Lourau: analista institucional em tempo integral. São Paulo: Hucitec, 2004. p. 47-65.

MENNANI, K. L. Pratiques des professionnels et dispositifs de soutien a la parentalité. Quelles places pour les parents et les enfants? Mémoire de recherche, master. Université Cergy-Pontoise, France, 2012.

MERHY, E. E. Saúde: a cartografia do trabalho vivo. São Paulo: Hucitec, 2002.

MONCEAU, G. Transformar as práticas para conhecê-las: pesquisa-ação e profissionalização docente. Educação e Pesquisa, [online], v. 31, n. 3, p. 467-482, set./dez. 2005. Disponível em: <http://www.scielo.br/pdf/ep/v31n3/a10v31n3>. Acesso em: 15 mar. 2014.

MONCEAU, G. Implicação, sobreimplicação e implicação profissional. Fractal, Rev. Psicol., Niterói, RJ, v. 20, n. 1, p. 19-26, jan./jun. 2008.

MONCEAU G. Travailler les interférences institutionnelles dans la ville. Diversité, [S.1.], n. 166, p. 42-47, 2011.

MONCEAU, G. (Org.). L'analyse institutionnelle des pratiques: une socioclinique des tourments institutionnels au Brésil et en France. Paris: L'Harmattan, 2012.

MOURÃO, L. C. et al. Análise institucional e educação: reforma curricular nas universidades pública e privada. Educ. Soc., Campinas, v. 28, n. 98, p. 181-210, jan./abr. 2007.

NASCIMENTO, M. L; SCHEINVAR, E. Intervenção socioanalitica em conselhos tutelares. Rio de Janeiro: Lamparina, 2010. 
PAULON, S. M.; ROMAGNOLI, R. C. Pesquisar, Intervir, Cartografar: melindres e meandros metodológicos. Estudos e Pesquisas em Psicologia, Rio de Janeiro, V. 10, p. 85-102, 2010.

PEREIRA, G. R. de M.; ANDRADE, M. da C. L. de. Socioanálise de pré-noções no discurso jornalístico sobre educação. Rev. Bras. Educ., Rio de Janeiro, n. 28, p. 128-139, abr. 2005.

PEZZATO, L. M.; L’ABBATE, S. O uso de diários como ferramenta de intervenção da Análise Institucional: potencializando reflexões no cotidiano da Saúde Bucal Coletiva. Physis, Rio de Janeiro, v. 21, n. 4, dez. 2011. Disponível em: <http:// dx.doi.org/10.1590/S0103-73312011000400008>. Acesso em: 15 mar. 2014.

ROCHA, M. L. Psicologia e as práticas institucionais: a pesquisa intervenção em movimento. PSICO, Porto Alegre, v. 37, n. 2, p. 169-174, maio/ago. 2006.

SPAGNOL, C. A.; L'ABBATE, S. Conflito organizacional: considerações teóricas para subsidiar o gerenciamento em enfermagem. Cienc Cuid Saude, [S.1.], v. 9, n. 4, p. 822-827, out./dez. 2010.

Recebido em: 22 de maio de 2014 Aceito em: 11 de julho de 2014 